\title{
Identifying thermo-mechanical induced microstructural changes
}

\author{
Seyed Morteza Zeinali ${ }^{1}$, and Sherif L. Abdelaziz ${ }^{1, *}$ \\ ${ }^{1}$ The Charles E. Via, Jr. Department of Civil and Environmental Engineering, Virginia Tech, Blacksburg, VA 24061, USA.
}

\begin{abstract}
Robust engineering of geomaterials for energy applications requires a clear understanding of the impacts of temperatures and pressures applied to the soil on their microstructures. Such understandings will facilitate better designs of new geomaterials and technologies via ensuring accurate assessments of the performance of the existing ones. In this study, we assess the changes in the microstructure-specific surface area and pore size distribution - of a saturated clay subjected to stress and temperature cycle. Clay specimens were subjected to the desired mechanical stresses and thermal cycles in a triaxial system. Then, the specimens were swiftly extracted from the triaxial, flush frozen in liquid nitrogen, then freezedried to preserve their microstructure. The preserved specimens were then used for specific surface area and pore size distribution assessments using nitrogen $\left(\mathrm{N}_{2}\right)$-gas adsorption and mercury intrusion porosimetry. The results established qualitative explanations of the expected microstructural changes in geomaterials under operational conditions, which facilitate the development of new geomaterials that can overcome such alternations.
\end{abstract}

\section{Introduction}

Engineering new geomaterials rely on recognizing the unfavored responses of existing ones under different loading conditions and resolving the associated problems. The techniques to overcome such unfavored behaviors of existing geomaterials mandate adopting a bottom-up engineering approach. In this approach, new geomaterials will need to be engineered at the small (i.e., micro) scale to have favorable large (i.e., macro) scale behaviors. Thus, we first need to identify the effects of each external loading condition on the geomaterial micro-scale and relate these microstructural changes to macro-scale responses. In this study, we identify the thermallyinduced pore structure changes of a saturated clay due to a temperature cycle with the overarching aim to guide the development of new geomaterials or treatments to limit these changes as desired.

Based on our experimental results, we recognize that:

(1) the pore size distribution is sensitive to temperature on both extremes (i.e., heating and freezing).

(2) The evolution of specific surface area is more significant when clay is subjected to elevated temperatures than freezing temperatures.

In this paper first, the experimental procedures of microstructural study are introduced and the results are discussed. Several new applications have increased the interest to investigate the thermal and mechanical behavior of soils including energy foundations, nuclear waste repository, and the deteriorating national infrastructure. Depending on the considered application, the temperature range of interest varies from temperatures below zero for arctic systems [1, 2], through soils under freezing-thawing cycles [3-5], to elevated temperatures and heating-cooling cycles [6-13].

We currently know that freezing cohesive soils increases their void ratio due to the thermal expansion of pore water as it turns into ice [14-17]. Additionally, we also know that thawing frozen clay results in an overall volume contraction associated with reductions in the void ratio $[4,18]$. Despite this decrease in the void ratio, the hydraulic conductivity of a saturated clay after freezingthaw cycles was reported to increase $[19,20]$. Such unexpected contradicting behavior was attributed to changes in soil microstructure due to freezing and thawing [14]. On the other temperature extreme, we know that normally consolidated saturated clays experience thermoplastic contractions upon heating [21,22]. These thermoplastic contractions occur as heating initially develops pore water pressures [23]. These generated pore water pressures decrease the effective stress [24] causing the physicochemical bonds between clay particles to become weak [25]. These softened bonds trigger partially collapse

\footnotetext{
${ }^{*}$ Corresponding author: saziz@vt.edu
} 
of the clay structure through particle reorientations [15, 16] These thermally induced changes in the clay microstructure alter its mechanical response including shear strength and stiffness.

\section{Materials and Sample Preparation}

\subsection{Materials}

All the experiments performed in this study used Edgar Plastic Kaolin (EPK) from Edgar, FL. This clay has 100\% of its particles finer than $25 \mu \mathrm{m}$ as determined using hydrometer analysis according to ASTM D7928-17 [26]. More than $96 \%$ of the EPK clay minerals were identified as kaolinite minerals [16]. The EPK clay, however, classifies as clay with high plasticity $(\mathrm{CH})$ according to the unified soil classification system (USCS) with plastic and liquid limits of 32 and $67 \%$, respectively $[14,16]$.

\subsection{Sample preparation}

Initially, the clay bulk samples were prepared under onedimensional consolidation. For this purpose, the EPK clay powder was mixed with deionized water at 1.5 the liquid limit. The slurry was then poured into a compaction mold and was subjected to one-dimensional consolidation under only the weight of the loading cap $(\sim 1 \mathrm{~kg})$ for 24 hours. Afterward, the consolidation was carried out under incremental loading up to a maximum vertical stress of $100 \mathrm{kPa}$. Afterward, the clay blocks were extruded from the molds.

Five triaxial specimens, with $\sim 35 \mathrm{~mm}$ diameter and $\sim 76 \mathrm{~mm}$ height, were trimmed out of these blocks. To assess the consistency of the sample preparation procedure in this study, the initial microstructure of the trimmed samples was first evaluated. For this purpose, representative samples with a thickness of $5 \mathrm{~mm}$ were taken from the top of the cut soil from each triaxial sample. The microstructures of the samples used for this assessment were preserved using flash-freezing by immersing them into liquid nitrogen $\left(\mathrm{N}_{2}\right)$ for 15 minutes followed by freeze-drying for 24 hours.

\subsection{Samples for post thermal cycles assessment}

The trimmed cylindrical triaxial specimens were mounted in a thermo-mechanical triaxial apparatus manufactured by GDS instruments. This apparatus is able to change the temperature of the specimens between $-20{ }^{\circ} \mathrm{C}$ to $+65^{\circ} \mathrm{C}$ using an internal coil connected to an external temperature control unit. Once mounted, each specimen was first saturated to a minimum Skempton pore water parameter $\mathrm{B}$ of at least 0.95 . Then, the specimens were isotopically consolidated under $400 \mathrm{kPa}$ effective stress at $20{ }^{\circ} \mathrm{C}$ constant temperature. These saturation and consolidation stages were performed under the top "single" drainage condition, i.e., the bottom drainage line was closed. After consolidation, each specimen was subjected to its respective thermal cycles (Table 1) with access to water supply from the top only (i.e., single drainage).
When the thermal cycle for each specimen was completed, the specimen was swiftly extracted from the triaxial cell. The triaxial sample for Isothermal Consolidation was extracted out of the triaxial cell right after the consolidation stage at $20^{\circ} \mathrm{C}$, i.e., without any temperature cycles, to evaluate the effects of saturation and consolidation on the microstructure of the soil. Evaluating these effects allows comparing the initial preand final post-thermal cycle fabrics. Representative samples were taken from the top of each specimen using a thin wire. These representative samples were then freeze-dried following the same procedure used for the initial representative samples taken from the triaxial sample.

Table 1. Temperature cycles used for each sample in this study.

\begin{tabular}{l|l}
\hline \hline Sample Name & Temperature Cycles $\left({ }^{\circ} \mathbf{C}\right)$ \\
\hline Isothermal Consolidation & 20 \\
\hline Freezing (F) & $20 \rightarrow(-20)$ \\
\hline F-Thawing (FT) & $20 \rightarrow(-20) \rightarrow 20$ \\
\hline FT-Heating (FTH) & $20 \rightarrow(-20) \rightarrow 65$ \\
\hline FTH-Cooling (FTHC) & $20 \rightarrow(-20) \rightarrow 65 \rightarrow 20$ \\
\hline \hline
\end{tabular}

Subsequently, $\mathrm{N}_{2}$-gas sorption was performed using NOVA 2200e surface area analyzer apparatus to measure the specific surface area (SSA) using Brunauer-EmmettTeller (BET) method. This method explains the physical adsorption of gas molecules to a solid surface by extending Langmuir's unimolecular layer theory [27]. Additionally, the pore size distributions of the representative samples were measured using mercury intrusion porosimeter (MIP) Quantachrome Poremaster.

\section{Results and discussions}

BET analysis and mercury intrusion experiments were performed on representative samples obtained from the cut soil from the triaxial samples to assess the uniformity of the initial state of microstructure among all triaxial samples. Table 2 presents the results of specific surface area measurements for samples at the top of the clay bulk mold which was prepared under one-dimensional consolidation under $100 \mathrm{kPa}$. The average specific surface area was $34.81 \mathrm{~m} 2 / \mathrm{gm}$ and the standard deviation was \pm 1.27 . Fig. 1 demonstrates the results of mercury intrusion for 4 samples representing the initial microstructure. There exists a good agreement between all pore size distributions in Fig. 1 indicating that in this study is satisfactory to produce comparable microstructures.

Table 2. Specific surface area (SSA) measurement results of initial samples from soil cut from triaxial samples.

\begin{tabular}{c|c|c|c}
\hline \hline Sample & \multicolumn{3}{|c}{ SSA $\left(\mathbf{m}^{2} / \mathbf{g}\right)$} \\
\hline \multirow{2}{*}{ Initial } & 34.407 & 34.407 & 33.922 \\
\cline { 2 - 4 } & 34.139 & 34.923 & 35.438 \\
\hline \hline
\end{tabular}




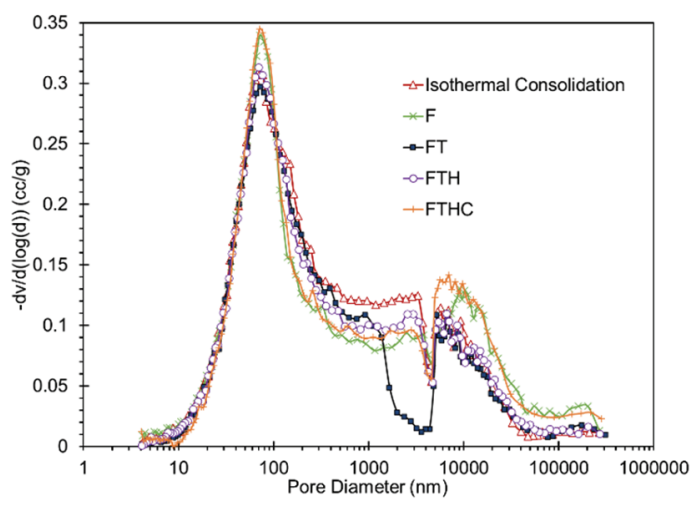

Fig. 1. Pore size distribution from the representative samples taken from the top of trimmings.

\subsection{Consolidation impact on PSD}

The pore size distribution (PSD) as well as the volume of intruded mercury normalized by the sample initial weight for Isothermal Consolidation at the top and its respective trimming sample are presented in Fig. 2. The peak of the curves in Fig. 2(a) represents the dominating pore diameter within each sample [2,28].

\subsection{Impacts of thermal cycles on PSD}

Fig. 3 overlays the pore size distribution and normalized intruded volume of mercury into the representative

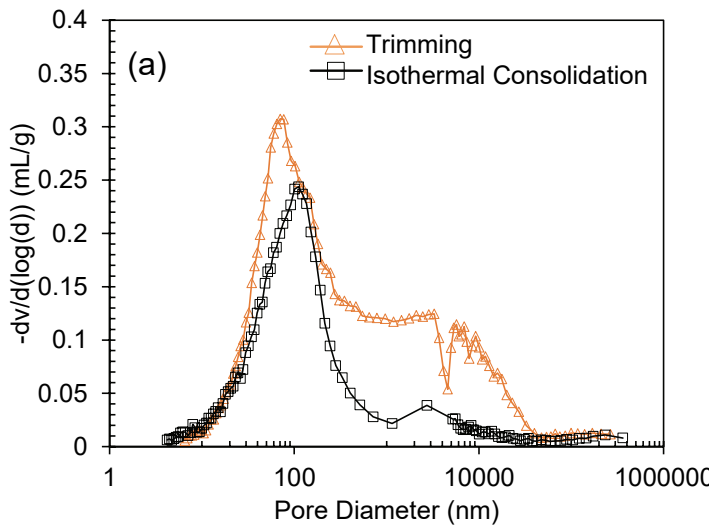

Fig. 2. Pore size distribution (a) and normalized intruded volume (b) for samples from the top of Isothermal Consolidation and trimming

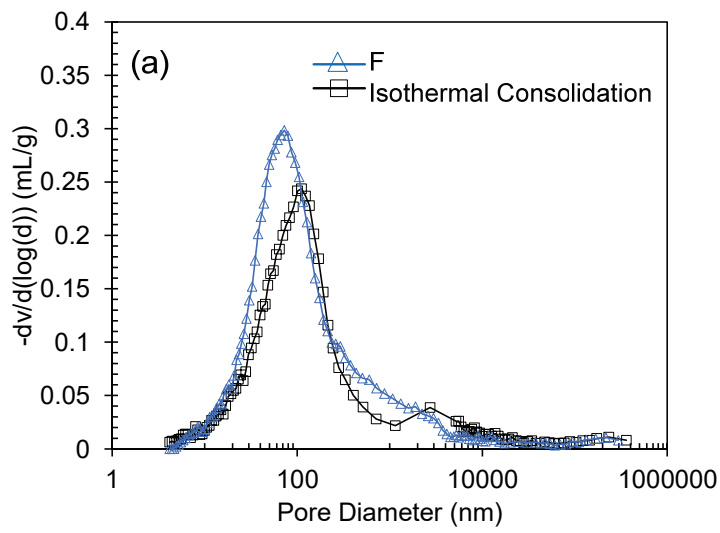

Fig. 3. Pore size distribution (a) and normalized intruded volume (b) for samples from the top of Isothermal Consolidation and after freezing.

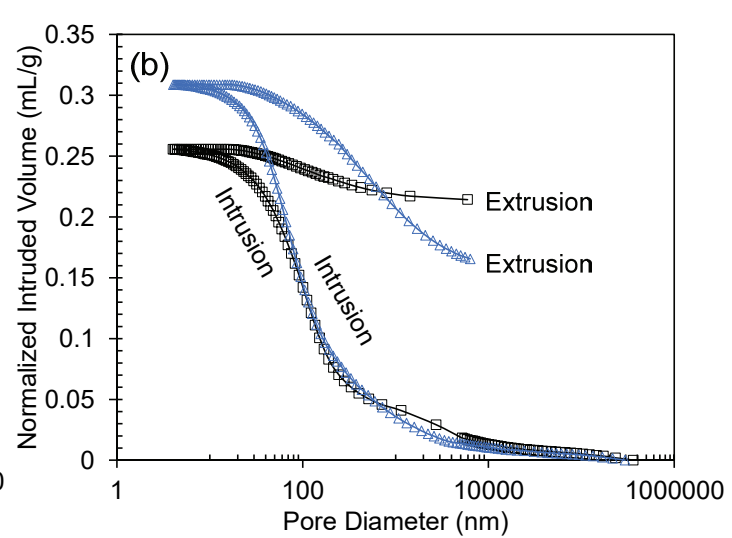

samples taken from the top of Isothermal Consolidation and Frozen samples. The results suggest that during freezing process, pores with sizes ranging 10 to $100 \mathrm{~nm}$ were generated while the pores with diameter more than $100 \mathrm{~nm}$ remained about the same. These newly generated pores increased the volume of pores with diameters less than $100 \mathrm{~nm}$ and as a result the dominant pore diameter became smaller comparing to the sample after mechanical consolidation.

Going to thawing, the excess water in the sample, sucked into the sample due to the negative pore water pressure during freezing, seeped out of the sample as it thaws. Because of this outflow of pore water, the pores tended to shrink and recover their initial diameter. The comparison between the microstructure at the end of mechanical consolidation and freezing thawing cycle is presented in Fig 4. As per Fig. 4(b), the total volume of pores after freezing thawing was higher comparing to Isothermal Consolidation sample. On the other hand, Fig. 4(a) shows almost identical pore size distribution before and after freezing and thawing cycle. X-ray diffraction studies on effect of temperature change on particle orientation of kaolinite clay reveals that the particles were reoriented during freezing; in the other words, freezing a sample deformed the shape of the pores by particle reorientation and sliding, on the other hand, the induced reorientation during freezing was more or less recovered under thawing [23]. Considering this phenomenon and the porosimetry results, in a freezing-thawing cycle the

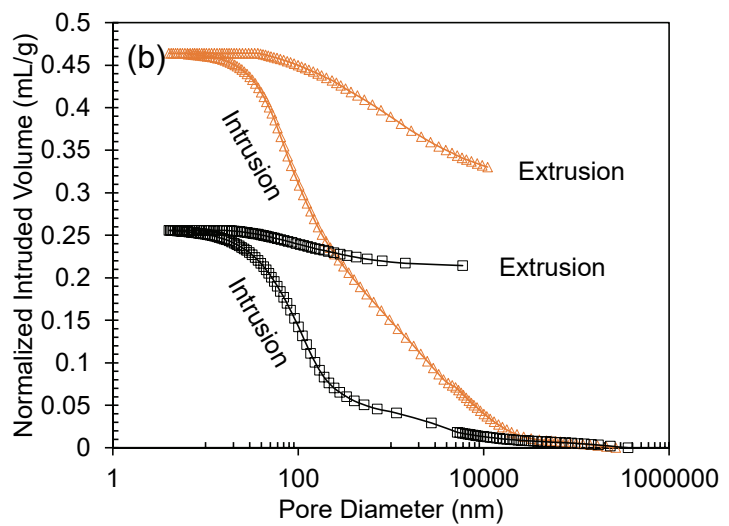



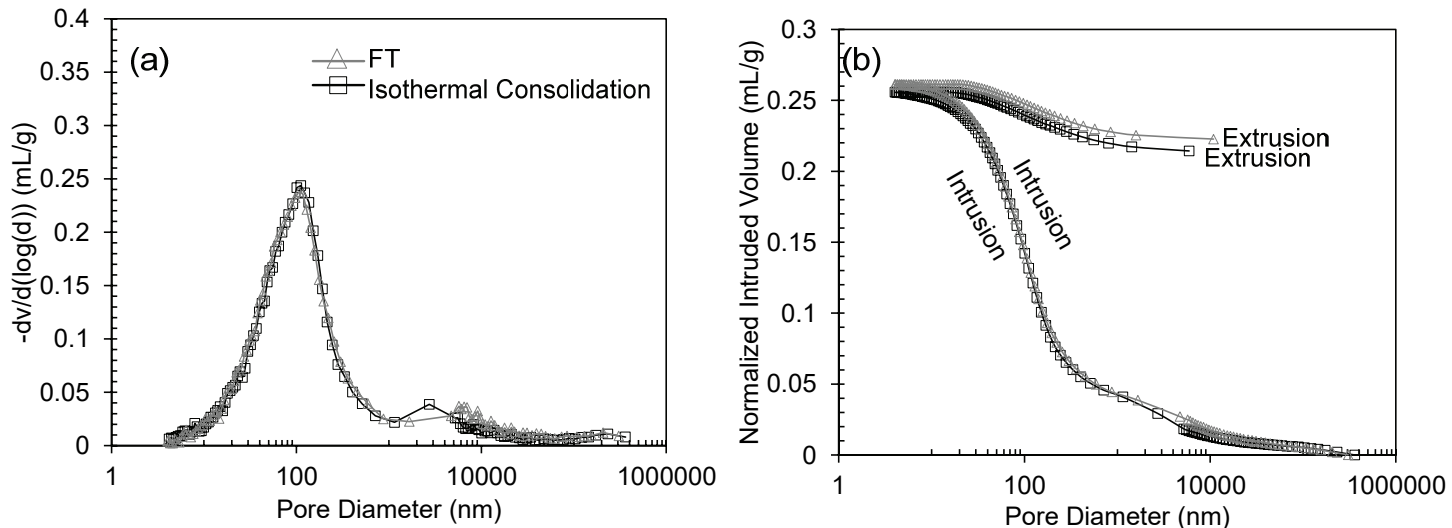

Fig. 4. Pore size distribution (a) and normalized intruded volume (b) for samples from the top of Isothermal Consolidation and Freezing-Thawing.
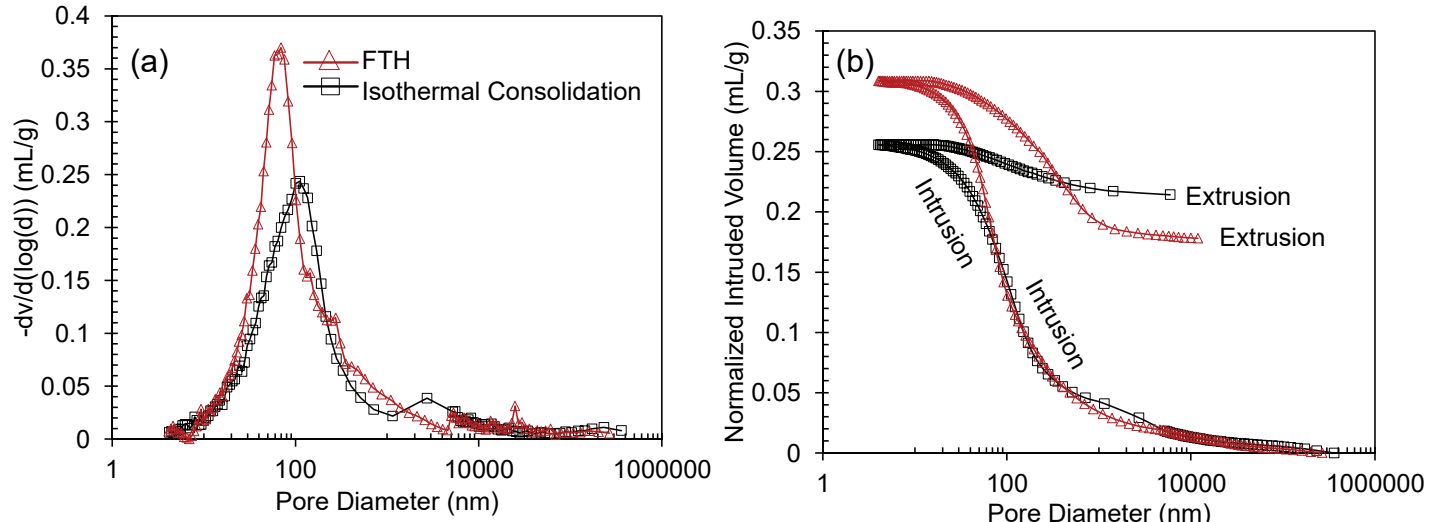

Fig. 5. Pore size distribution (a) and normalized intruded volume (b) tor samples trom the top of Isothermal Consolidation and Freezing-Thawing-Heating.

plastic reorientation of clay particles as well as the generated microcracks during freezing prevents a complete pore size recovery after thawing.

Moreover, the microstructural change due to heating at the top of the sample is presented in Fig. 5. While the dominant pore diameter was smaller after the elevated temperature, the total volume of the pores increased. This observed phenomenon suggests that while the water flows out during heating, the large pores not only shrank but also

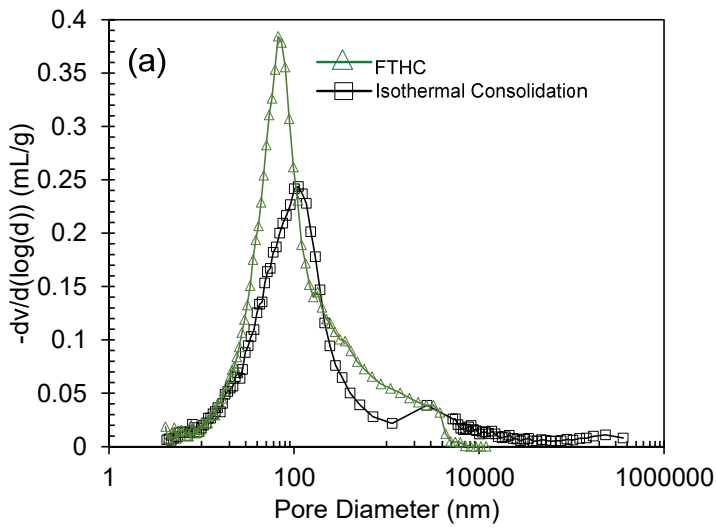

A plastic contraction resulting in smaller pores can be observed at the end of cooling which agrees with previous studies on heating normally consolidated clays $[17,18]$.

\subsection{Temperature cycle impact on SSA}

Three gas sorption experiments were done on representative samples taken from the top and bottom of triaxial samples presented in Table 1 and the measured

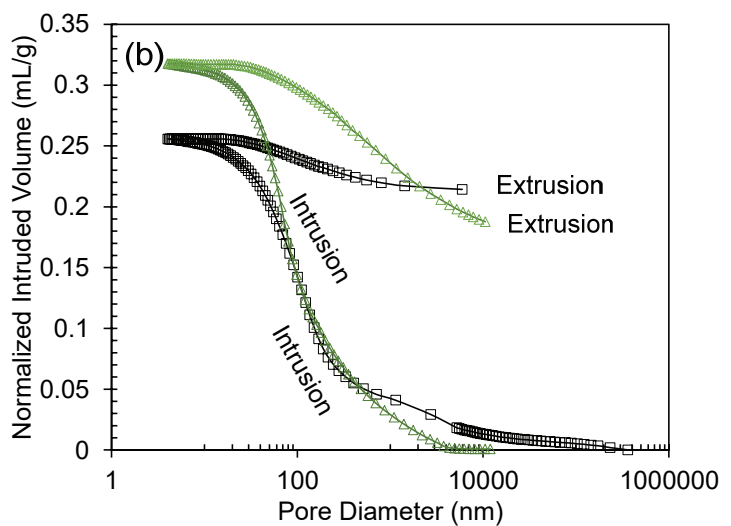

Fig. 6. Pore size distribution (a) and normalized intruded volume (b) for samples from the top of Isothermal Consolidation and Freezing-Thawing-Heating-Cooling. collapsed into a greater number of smaller pores. Finally, Fig. 6 presents the comparison of pore size distribution at the top of the sample at the end of a full temperature cycle. values are listed in Table 3. The results were then averaged for Isothermal Consolidation sample as 
Table 3. Measure and average values of specific surface area.

\begin{tabular}{c|c|c|c|c}
\hline \hline SAMPLE & \multicolumn{3}{|c|}{ SSA (m $\mathbf{~} \mathbf{g})$} & Avg. $\left(\mathbf{m}^{\mathbf{2}} / \mathbf{g}\right)$ \\
\hline Isothermal Consolidation & 33.995 & 33.242 & 31.822 & 33.020 \\
\hline Freezing & 35.386 & 34.891 & 33.601 & 34.626 \\
\hline Freezing-Thawing & 34.995 & 34.105 & 32.063 & 33.721 \\
\hline Freezing-Thawing-Heating & 34.475 & 35.899 & 31.314 & 33.896 \\
\hline Freezing-Thawing-Heating-Cooling & 33.083 & 34.101 & 34.086 & 33.757 \\
\hline \hline
\end{tabular}

well as each temperature change. The measured values of SSA for each temperature change were compared to the microstructural measurements of the Isothermal Consolidation samples. The percentages of the change in the specific surface area for each sample are presented in Fig 7. Gas sorption results suggest that specific surface area increases as the temperature of the sample varies Finally, the increase in specific surface area at the end of the thermal cycle was irreversible and did not recover the initial value. This phenomenon displays the non-elastic change in the microstructure of the normally-consolidated clay.

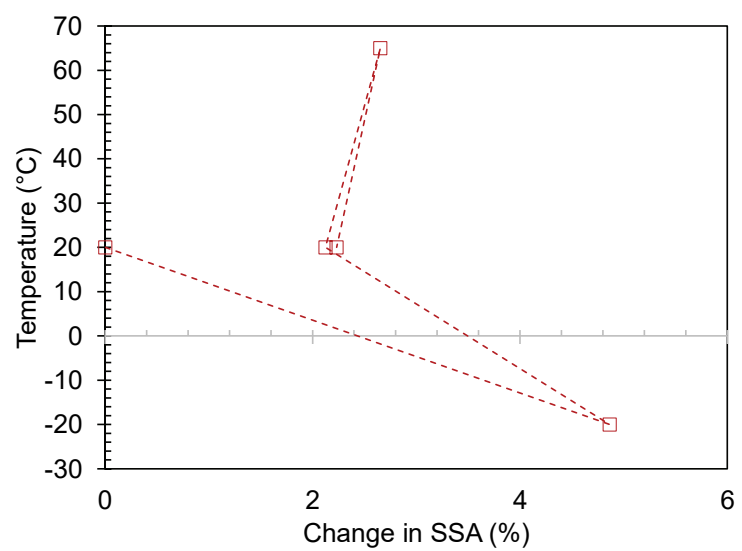

Fig. 7. Change in specific surface area versus temperature at the top of the sample.

\section{Conclusion}

In this study, the evolution of the microstructure of a saturated kaolinite clay under mechanical consolidation and under each stage of a temperature cycle was evaluated. For this purpose, five triaxial kaolinite clay samples were consolidated under $400 \mathrm{kPa}$, and then each sample was subjected to a specific thermal path. These temperature changes completed a freezing-thawingheating-cooling cycle. Representative samples from the top and bottom of triaxial samples, extracted after mechanical consolidation, and each thermal path was taken. Flash freezing and freeze-drying techniques were then used to preserve the microstructure of each sample. afterward, the pore size distribution and specific surface area of measured using mercury intrusion and BET method. The dominant pore size and total volume of the pores decreased due to mechanical consolidation, however freezing increased both. Furthermore, as thawing almost recovered the initial pore size distribution, the plastic changes of microstructure maintained the higher pore volume. Moreover, heating decreased the dominant pore size while increased the total volume of the pores which require more investigation. Finally, after cooling, the irreversible change in pore size distribution and total volume of pores was observed. However, the specific surface area increased throughout the thermal cycle comparing to the initial value suggesting the change of not only pore volume but also pore shape and number of the pores.

Research was sponsored by the Army Research Office and was accomplished under Grant Numbers W911NF16-1-0336, W911NF-18-1-0068 and W911NF-20-10238. The views and conclusions contained in this document are those of the authors and should not be interpreted as representing the official policies, either expressed or implied, of the Army Research Office or the U.S. Government.

\section{References}

1. J. Cohen, K. Rautiainen, J. Ikonen, J. Lemmetyinen, T. Smolander, J. Vehviläinen, and J. Pulliainen," Detection of Soil Frost in the Boreal Forest Region with Sentinel-1", in EGU General Assembly Conference Abstracts of Conference, (2018).

2. Z.-L. Zhang and Z.-D. Cui (2018)," Effects of freezing-thawing and cyclic loading on pore size distribution of silty clay by mercury intrusion porosimetry", Cold. Reg. Sci. Technol., 145, 185-196.

3. Z. Yuanlin and D. Carbee (1984)," Creep behavior of frozen silt under constant uniaxial stress", J. Glaciol. and Geocry., 6(1), 33-48.

4. E. Simonsen and U. Isacsson (1999)," Thaw weakening of pavement structures in cold regions", Cold. Reg. Sci. Technol., 29(2), 135-151.

5. N.T. Morgenstern and J. Nixon (1971)," Onedimensional consolidation of thawing soils", Can. Geotech. J., 8(4), 558-565.

6. S.L. Abdelaziz and T.Y. Ozudogru (2016)," Selection of the design temperature change for energy piles", Appl. Therm. Eng., 107, 1036-1045.

7. S.L. Abdelaziz, T.Y. Ozudogru, C.G. Olgun, and J.R. Martin II (2014)," Multilayer finite line source model for vertical heat exchangers", Geothermics, 51, 406416.

8. C.G. Olgun, S.L. Abdelaziz, and J.R. Martin, (2012)," Long-Term Performance and Sustainable Operation of Energy Piles", in Proc. International Conference on Sustainable Design, Engineering, and Construction p. 534-542.

9. C.G. Olgun, T.Y. Ozudogru, S.L. Abdelaziz, and A. Senol (2014)," Long-term performance of heat exchanger piles", Acta Geotechnic., 10(5), 553-569. 
10. H. Brandl," Energy piles for heating and cooling of buildings", in Seventh International Conference \& Exhibition on Pilling and Deep Foundations. of Conference, (1998).

11. H. Abuel-Naga, D. Bergado, A. Bouazza, and G. Ramana (2007)," Volume change behaviour of saturated clays under drained heating conditions: experimental results and constitutive modeling", Can. Geotech. J., 44(8), 942-956.

12. S.M. Zeinali and S.L. Abdelaziz, (2020)," Effect of Heating Rate on Thermally Induced Pore Water Pressures and Volume Change of Saturated Soils", in Geo-Congress 2020. p. 31-39.

13. K. Jaradat and S. Abdelaziz, (2018)," Temperaturedependent load-displacemet curves of heat exchanger piles in sand", in IFCEE 2018. 2018. p. 686-695.

14. Z. Darbari, K.A. Jaradat, and S.L. Abdelaziz (2017)," Heating-freezing effects on the pore size distribution of a kaolinite clay", Environ. Earth Sci.s, 76(20), 713.

15. S.L. Abdelaziz, K.A. Jaradat, and S.M. Zeinali (2020)," Modified Thermomechanical Triaxial Cell for Microscopic Assessment of Clay Fabric Using Synchrotron X-Ray Diffraction", Geotech. Test. J., 43(4).

16. K.A. Jaradat, Z. Darbari, M. Elbakhshwan, S.L. Abdelaziz, S.K. Gill, E. Dooryhee, and L.E. Ecker (2017)," Heating-freezing effects on the orientation of kaolin clay particles", Appl. Clay Sci., 150, 163174.

17. S.M. Zeinali and S.L. Abdelaziz, (2020)," FreezingThawing Effect on Saturated Clay Microstructure", in Geo-Congress 2020. p. 40-48.

18. E. Chamberlain, I. Iskandar, and S. Hunsicker (1990)," Effect of freeze-thaw cycles on the permeability and macrostructure of soils", Cold Region Research and Engineering Laboratory, 90(1), 145-155.

19. C.H. Benson and M.A. Othman (1993)," Hydraulic conductivity of compacted clay frozen and thawed in situ", J. of Geotech. Eng., 119(2), 276-294.

20. R.D. Hewitt and D.E. Daniel (1997)," Hydraulic conductivity of geosynthetic clay liners after freezethaw", J. Geotech. and Geoenviron., 123(4), 305313.

21. Jaradat, K. A., \& Abdelaziz, S. L. (2020). Thermomechanical Triaxial Cell for Rate-Controlled Heating-Cooling Cycles. Geotech. Test. J., 43(4).

22. C.J.R. Coccia and J.S. McCartney (2016)," Thermal volume change of poorly draining soils I: Critical assessment of volume change mechanisms", Comput. and Geotech. 80, 26-40.

23. K.A. Jaradat and S.L. Abdelaziz, (2020)," Microscopic Assessment of the Thermally Induced Volume Changes of Saturated Clays Using Discrete Element Method", in Geo-Congress 2020. p. 293301.

24. R.G. Campanella and J.K. Mitchell (1968)," Influence of temperature variations on soil behavior", J. Soil Mech. Found. Div., Am. Soc. Civ. Eng. , 94, 709-734.

25. T. Hueckel and G. Baldi (1990)," Thermoplasticity of saturated clays: experimental constitutive study", $J$.
Geotech. Eng., 116(12), 1778-1796.

26. J.K. Mitchell and K. Soga, (2005), " Fundamentals of soil behavior". Vol. 3: John Wiley \& Sons New York.

27. ASTM D7928-17 (2017), Standard Test Method for Particle-Size Distribution (Gradation) of FineGrained Soils Using the Sedimentation (Hydrometer) Analysis": ASTM International, West Conshohocken, PA, www.astm.org.

28. S. Brunauer, P.H. Emmett, and E. Teller (1938)," Adsorption of gases in multimolecular layers", J. Am. Chem. Soc., 60(2), 309-319.

29. S. Sasanian and T. Newson (2013)," Use of mercury intrusion porosimetry for microstructural investigation of reconstituted clays at high water contents", Eng. Geol., 158, 15-22. 